\title{
ANFITRIÕES: DELINEANDO O CONCEITO DE PÓS- HUMANO NA SÉRIE TELEVISIVA WESTWORLD
}

\section{HOSTS: DELINEATING THE CONCEPT OF POST-HUMAN ON THE TV SERIES WESTWORLD}

\author{
Lynn Rosalina Gama Alves* \\ Maria Carmem Souza**
}

\section{RESUMO}

O presente artigo parte da discussão sobre o pós-humano que vem crescendo ao longo dos últimos trinta anos, destacando especialmente a década de noventa quando pesquisadores do cenário internacional e nacional ampliaram o debate, a partir das hibridações entre o corpo e as inovações tecnológicas. Esta temática também vem sendo apresentada de distintas formas na literatura, como no clássico Frankenstein de Mary Shelley (1818); e na linguagem audiovisual com animações, histórias em quadrinhos, filmes e narrativas seriadas televisivas. É nesse contexto que se insere este artigo que, partindo da questão o que é ser pós-humano na sociedade contemporânea, dialoga com as produções fílmicas e séries televisivas, especialmente analisando a série Westworld, transmitida pelo canal HBO, desde o ano de 2016. O nosso objetivo é, tomando como referência a trama dessa série, discutir e refletir sobre a linha tênue que nos separa dos androides em uma sociedade em que, de certa forma, todos nós estamos nos tornando pós-humanos. Os resultados da análise estabelecendo relações entre a narrativa da série indicada e o contexto da sociedade contemporânea, especialmente os relacionados com espaços de aprendizagem escolar e acadêmico, apontam preocupações relacionadas com temas emergentes como vigilância, acesso indevido e antiético aos dados gerados e armazenados a partir de algoritmos, a interface homem/máquina, ações invasivas mediadas pelas tecnologias que são acopladas para potencializar funções cognitivas e, por fim, a questão da violência que tem retornado neste atual contexto mediado pelo medo. Embora os resultados não pareçam alvissareiros, destacamos que a emergência de novas formas de hibridação que favorecem a (re)construção do pós-humano nos permite explorar universos inusitados, potencializando novas formas de viver, aprender e amar na sociedade contemporânea, indo além de extensões e próteses para fundamentar práticas criativas e inovadoras, especialmente no cenário escolar e acadêmico.

Palavras-chave: Pós-humano. Westworld. Narrativas seriadas.

\section{ABSTRACT}

The present article stems from the debate on Post-human which has been gaining momentum over the last thirty years, especially the nineties, when national and international researchers widened the debate taking into consideration the hybridization between body and recent technological innovation. The theme has also been presented in distinct forms: in literature, such as the classic Mary Shelley's Frankenstein (1818); in audiovisual language by means

\footnotetext{
* Universidade Federal da Bahia (UFBA), Salvador, BA, Brasil. lynnalves@gmail.com, http://orcid. org/0000-0003-3688-3506

** Universidade Federal da Bahia (UFBA), Salvador, BA, Brasil. mcjacobsg@gmail.com, https://orcid. org/0000-0001-5519-8040
} 
of animation, cartoons, movies and TV series narratives. The present article lies within that context and stems from the question of what it is to be Post-human in the contemporary society in order to dialogue with filmic productions and TV series, especially analyzing the series Westworld, broadcast by HBO channel since 2016. Our aim is, taking the plot of that series as a reference, to discuss and to reflect upon the thin line that separates us from androids within a society where all of us are becoming, in a way, Post-human. The analysis results, while stablishing relations between the narrative of the indicated series and the context of contemporary society, point to preoccupations related to emerging themes such as vigilance, unauthorized and anti-ethical access through invasive actions mediated by technology which are attached in order to potentialize cognitive functions, among others and, finally, the question of violence that has returned in that context mediated by fear. Although the results do not seem as good news, we point out that the emergence of new forms of hybridization, which favor the (re)construction of Post-human, allows us to explore unthinkable universes, potentializing new forms of living, learning and loving within contemporary society, going beyond extensions and prostheses, in order to substantiate creative and innovative practices, especially in the school scene.

Key words: Post-human. Westworld. Serial narratives.

\section{SOBRE O PÓS-HUMANISMO}

A discussão em torno do pós-humanismo vem crescendo nos últimos trinta anos - seja por conta do avanço científico-tecnológico e, consequentemente, do reflexo destas inovações nas publicações acadêmicas como a de Haraway (2009) e Hayles (1999); seja por conta das distintas representações do que é ser póshumano nas artes (cinema, séries televisivas, jogos digitais, etc.). Mas o que é ser pós-humano? Esse questionamento vem marcando esse período e especialmente as produções e práticas na sociedade contemporânea, caracterizada pela presença das tecnologias digitais e telemáticas.

O presente artigo se insere neste Dossiê "O pós-humano é agora!", sintonizado com as perspectivas clássicas e contemporâneas sobre o tema, dialogando com as séries televisivas, especialmente Westworld - WW. O nosso objetivo é, tomando como referência a trama dessa série, discutir e refletir sobre a linha tênue que nos separa dos androides em uma sociedade em que, de certa forma, todos nós estamos nos tornando pós-humanos. Para Tadeu

Os ciborgues vivem de um lado e do outro da fronteira que separa (ainda) a máquina do organismo. Do lado do organismo: seres humanos que se tornam, em variados graus, "artificiais". Do lado da máquina: seres artificiais que não apenas simulam características dos humanos, mas que se apresentam melhorados relativamente a esses últimos. (2009, p. 11-12)

Partindo das ideias iniciais apontadas aqui, dividimos o artigo em três seções. A primeira se constitui em uma breve introdução do tema, na qual dialogamos com os 
autores que discutem o conceito de pós-humano e suas características. Na segunda seção tomamos como corpus de análise a série Westworld, que se apresenta como um fio borromeu no qual os seus personagens transitam entre androides e humanos, indicando que cada vez mais nos tornamos híbridos e nem sempre é possível separar em caixas o que nos diferencia. Ainda nessa seção discutimos o descompasso dos espaços de aprendizagens escolares e acadêmicos com as narrativas contemporâneas e o pós-humano.

E finalmente, na terceira e última seção, apresentamos as conclusões sintonizadas com nossas investigações em torno do que é ser pós-humano neste momento histórico que estamos vivendo.

\section{HUMANOS E CIBORGUES - 0 QUE NOS DIFERENCIA?}

Iniciamos dialogando com Rüdiger (2007), que aponta três momentos para situar a emergência do movimento humanista. Segundo o autor, Nietzsche foi o primeiro a falar da necessidade de se superar a espécie humana, marcando, assim, o início das discussões e práticas em torno desse movimento. Esse primeiro momento finaliza nos anos 1960, quando o grupo de pesquisadores influenciados por Wiener (embora a obra Cybernetics, or control and communication in the animal and machine tenha sido escrita em 1948) inicia o pensamento cibernético, caracterizando-se com o segundo momento. $\mathrm{O}$ termo cibernética tem origem no grego kybernetes e significa "o homem que dirige". Segundo Kunzru

\footnotetext{
Os seguidores de Wiener viram a cibernética como uma ciência que explicaria o mundo como um conjunto de sistemas de feedback, permitindo o controle racional de corpos, máquinas, fábricas, comunidades e praticamente qualquer outra coisa. A cibernética prometia reduzir problemas "confusos", em campos tais como a economia, a política e talvez a moral, à condição de simples tarefas de engenharia: uma coisa que se poderia resolver com lápis e papel ou, na pior das hipóteses, com um dos supercomputadores do MIT. (2009, p. 124-125)
}

As pesquisas iniciadas por esse grupo e em sintonia com as investigações sobre Inteligência Artificial (IA), coordenada por Marvin Minsk, em 1959, trouxeram contribuições significativas para o que mais tarde configurou as ciências cognitivas e as inovações no desenvolvimento computacional, contribuindo para delinear o conceito de pós-humano deixando para trás o termo cibernética.

Contudo, é importante ressaltar que a cibernética deixou duas importantes contribuições: a) descrição do mundo como uma coleção de redes; b) os cibernéticos intuíram que, ao contrário do que se acreditava, não existia uma distinção clara entre pessoas e máquinas. Estas ideias marcam hoje todo o processo de desenvolvimento 
tecnológico com suas pesquisas e seus desdobramentos na indústria, na saúde, na educação.

$\mathrm{O}$ aprofundamento do conceito de redes complexas foi fundante para compreender a organização da sociedade, isto é, o ambiente e seus distintos ecossistemas. Haraway (1985) já apontava no seu livro Manifesto do ciborgue que estamos interligados por meio das redes; redes biológicas que em interação com as tecnologias vêm (re) construindo nossos corpos, nos tornando híbridos de "carne e metal", sinalizando o imbricamento homem/máquina.

As redes também estão dentro de nós. Nossos corpos, nutridos pelos produtos da grande indústria de produção de alimentos, mantidos em forma sadia - ou doentia - pelas drogas farmacêuticas e alterados pelos procedimentos médicos, não são tão naturais quanto a empresa Body Shop quer nos fazer crer. A verdade é que estamos construindo a nós próprios, exatamente da mesma forma que construímos circuitos integrados ou sistemas políticos - e isso traz algumas responsabilidades. (KUNZRU, 2009, p. 24)

Para Kunzru, embora de forma controversa, esses "conceitos estão no coração biônico do ciborgue" $(2009,126)$. Na perspectiva de Tadeu (2009) esses processos envolvendo a mecanização e eletrificação do humano, bem como a humanização e subjetivação da máquina, marcaram o nascimento dessa criatura pós-humana, o ciborgue. Esse ciborgue se assemelha ao humano nas suas ações e comportamentos, mas não possui nenhuma racionalidade, sendo feito de fluxos, circuitos e fios e silícios. O autor nos desafia a integrar a corrente, plugar e se ligar a uma tomada ou a uma máquina ou a outro humano ou ciborgue. "Torne-se um: devir-ciborgue. Eletrifique-se. O humano se dissolve como unidade. É só eletricidade. Tá ligado?" (TADEU, 2009, p. 14).

Tadeu também discute essas relações e suas interfaces com o currículo escolar, desde os anos noventa, nas obras que organizou, especialmente no livro Pedagogia dos monstros (2000) e Alienígenas na sala de aula, (SILVA, TADEU, 1995). No primeiro livro, os autores que participaram da obra, analisam as tensões que marcam o processo de formação da subjetividade, utilizando a análise ficcional dos monstros como metáforas, a partir do diálogo com os Estudos Culturais.

As contribuições dos pesquisadores como Hayles (1999), Haraway (2009), Kunzru (2009), Tadeu (2009) entre outros delinearam o início da "era do ciborgues", nos anos noventa.

O terceiro momento, na perspectiva de Rüdiger (2007), se inicia na década de 80 e se estende até os nossos dias, estruturando e organizando grupos simpatizantes da ideia do pós-humano. Para este autor, os defensores do movimento, a exemplo de More (1994), apontam que o ser pós-humano possui capacidades 
físicas e intelectuais sem precedentes, é uma entidade possuidora de princípios de autoformação potencialmente imortal, caracterizando-se como ciborgue ou uma máquina de inteligência artificial. Em contraponto, Rüdiger (2007), citando Jahn, apresenta uma perspectiva mais negativa do movimento apontando-o como uma "confusão intelectual, estupidez e desejo horrendo, elaborado em uma ideologia consciente, aplicada ao conjunto das tecnologias potencialmente definidoras do século 21" (JAHN apud RÜDIGER, 2007, p. 3).

Mas Rüdiger (2007), pontuando uma postura crítica sobre o movimento, já sinalizava em 2007 que já estamos vivendo um momento de profunda modificação da condição humana mediada por tecnologias como realidade virtual, a engenharia genética e próteses de todos os tipos, inclusive de mudança de sexo, que sinalizam esta transformação. Uma transformação que vai além das extensões e próteses, caracterizando processos de criação e invenção (KASTRUP, 2000).

Em diálogo com Lévy (1993) a autora já apontava que os dispositivos técnicos provocam a busca de solução de problemas, produzindo a invenção de problemas. "As situações problemas são aquelas para as quais o organismo não dispõe de respostas prontas em seu repertório de comportamentos e os dispositivos técnicos funcionam como meios para alcançar esse fim" (KASTRUP, 2000, p. 39). É dentro desse contexto que se insere o pós-humano e que para Tadeu (2009), em interlocução com Gray et. al (1995), as tecnologias ciborguianas podem ser restauradoras, normalizadoras, reconfiguradoras e melhoradoras.

E por fim Rüdiger (2007) pontua que esta discussão vem se espalhando por diferentes campos, a exemplo da literatura, da ficção científica, do cinema e das investigações dentro das universidades, ilustrando também que os ciborgues já estão entre nós e não são meras ficções, como Kevin Warwick ${ }^{1}$, Wendy Carlos², Stephen Hawkins ${ }^{3}$, entre outros (RÜDIGER, 2007).

E como as séries televisivas, especialmente Westworld (WW), vêm apresentando o movimento pós-humano? E de que forma essas séries podem dialogar com os espaços de aprendizagem escolar e acadêmico? A série WW apresenta uma

1. Kevin Warwick tornou em 1998 o primeiro ciborgue do mundo ao implantar um microchip no seu braço esquerdo para controlar um braço remoto. Disponível na URL: https://www.youtube.com/ watch?v=GLq7edATaFo . Acesso 21 Jan. 2019.

2. Walter Carlos fez cirurgia para mudança de sexo em 1972, tornando-se Wendy Carlos musicista americana, pioneira na música eletrônica, responsável por trilhas sonoras de filmes de Stanley Kubrick. Disponível na URL: https://jconline.ne10.uol.com.br/canal/cultura/musica/ noticia/2018/11/02/wendy-foi-pioneira-na-musica-eletronica-quando-se-chamava-walter-360654. php. Acesso 21 Jan. 2019.

3. Físico britânico com Esclerose Lateral Amiotrófica - ALS, que utilizava dispositivos para se comunicar e movimentar devido às perdas sofridas com a doença. 
perspectiva reconfiguradora, isto é, a criação de criaturas pós-humanas que são iguais aos seres humanos e ao mesmo tempo diferente deles (GRAY et. all apud TADEU, 2009, p. 11 -12). Outro ponto importante a destacar sobre os ciborgues da série é a informação, característica, segundo Haraway (2009), que os diferencia dos seus ancestrais mecânicos. Em uma entrevista dada a Kunzru, a autora aponta que os ciborgues contemporâneos "são máquinas de informação. Eles trazem dentro de si sistemas causais circulares, mecanismos autônomos de controle, processamento de informação - são autômatos com uma autonomia embutida" (2009, p. 123).

Essas máquinas de informação estão presentes no nosso cotidiano de distintas formas, a exemplo das assistentes virtuais como a Siri do sistema operacional IOS, e a Alexa da Amazon que através do comando de voz possibilita o acesso aos aplicativos e informações. Segundo os desenvolvedores, no primeiro trimestre de 2016 Alexa tinha apenas 135 habilidades e em junho de 2017 mais de $15 \mathrm{mil}^{4}$, alcançando no quarto trimestre de 2018 o número de 80 mil habilidades (ou comandos de voz) ${ }^{5}$. Contudo, essa quantidade de novas habilidades não significa qualidade, segundo pesquisa realizada pela agência de marketing digital Stone Temple em 2017.

Enquanto o Google Assistant (no Google Home) foi capaz de responder 68,1\% das perguntas, a Alexa respondeu somente $20,7 \%$ delas. A Siri ficou em segundo lugar, respondendo $56,5 \%$ das perguntas, e a Cortana, terceira colocada, respondeu apenas $21,7 \%$. Na precisão das respostas, porém, a Alexa se saiu muito melhor: ficou em segundo lugar, com $87 \%$, atrás apenas do Google Assistant, com 90,6\%. A Siri ficou em terceiro, com $81,9 \%$, e a Cortana ficou em último, com $62,2 \%{ }^{6}$

Assim, através das técnicas de machine learning essas assistentes, dentre outras tecnologias, aprendem junto conosco a responder às nossas necessidades, demandas e desejos de novas informações ou até atuando como interlocutoras diante da solidão que aflige o mundo contemporâneo, como bem retratado na ficção através do filme She (Ela), dirigido por Spike Jonze (2013), no qual um homem solitário desenvolve uma relação afetiva com sua assistente virtual. Ou ainda o personagem Raj, da série Big Ben Theory, produzido por Chuck Lorre e em exibição desde 2007 -

4. ISBITSKI, David. Build Skills for Echo Show: New Alexa Skills Kit Features for Display and Video Interfaces. In: 28 Jun. 2017. Disponível na URL: https://developer.amazon.com/de/blogs/alexa/ post/50d2ed06-6a81-415c-a842-b335c7f967df/build-skills-for-echo-show-new-alexa-skills-kitfeatures-for-display-and-video-interfaces?tag=bisafetynet-20. Acesso 02 Abr. 2019.

5. VENTURA, Ivan. Amazon: Alexa ultrapassa a marca de 80 mil habilidades de comando de voz. 02 Fev. 2019. Disponível na URL: https://www.consumidormoderno.com.br/2019/02/04/alexamarca-80-mil-comando-voz/. Acesso 02 Abr. 2019.

6. CIRIACO, Douglas. Assistente virtual da Amazon, Alexa já conta com mais de 15 mil habilidades

Disponível na URL: https://www.tecmundo.com.br/software/118816-assistente-virtual-amazon-aexaconta-15-mil-habilidades.htm. Acesso 02 Abr. 2019. 
2019 ${ }^{7}$, que cria um vínculo com sua assistente virtual, na temporada 5, episódio 14. Esse vínculo que vamos criando com essas tecnologias e bancos de informação vem fazendo parte de nossas vidas, como se não fosse possível mais viver sem elas. Tal perspectiva aponta outros delineamentos do pós-humano.

O sétimo relatório World Happiness Report 2019, publicado em março de 2019, aponta os resultados da pesquisa realizada com 156 países; e no seu capítulo The Sad State of Happiness in the United States and the Role of Digital Media apresenta o papel da interação com o universo digital, nos Estados Unidos ${ }^{9}$, especialmente por parte dos jovens que passam muito tempo em frente a distintas telas, criando novos vínculos através dos ambientes interativos, não dedicando muito tempo às relações face to face. Desse modo, essas telas estão acopladas aos pós-humanos no século XXI.

\section{DE QUE LUGAR VAMOS FALAR?}

Para iniciar é importante destacar que compreendemos que o homem póshumano é aquele que interage com as mudanças tecnológicas tanto em nível das modificações no seu corpo quanto no que se refere a questões cognitivas, afetivas, sociais, econômicas e políticas. Kunzru (2009) chama nossa atenção para o fato de que ser ciborgue não tem a ver com quantas próteses ou bits de silício tem em nosso corpo; tem a ver com os energéticos que consumimos, com os equipamentos que utilizamos nas academias, como os adereços que vestimos como os calçados especiais que usamos para melhorar nossa performance, com as pulseiras para monitorar nosso corpo, a exemplo da Fitbit.

Para o autor o ciborgue se constitui em uma criatura da realidade social, mas também da ficção. Realidade social compreendida como assignificações das relações sociais vividas, das construções políticas e das ficções que podem mudar o mundo. Desta forma, todos nós já somos pós-humanos, considerando que nosso cotidiano vem sendo mediado pelas tecnologias para ampliar nossas diferentes possibilidades de interação com o mundo e com o outro; seja através de uma prótese no joelho, implantes neurais, um marca-passo no coração ou a mediação de pulseiras que avaliam nossa performance, inclusive registrando os batimentos

7. Já foi noticiada que em 2019 termina as temporadas da série

8. World Happiness Report 2019. Publish 20 march 2019. Disponível na URL: http://worldhappiness. report/ed/2019/\# read. Acesso 02 Abr. 2019.

9. TWENGE, Jean M. The Sad State of Happiness in the United States and the Role of Digital Media - Chapter 5. Publish 20 march 2019, Disponível na URL: http://worldhappiness.report/ed/2019/ the-sad-state-of-happiness-in-the-united-states-and-the-role-of-digital-media/ . Acesso $02 \mathrm{Abr}$. 2019. 
cardíacos, caracterizando o que Lemos e Bitencourt (2018) vêm denominando de sensibilidade performativa.

Neste cenário, o conceito de tecnologia sintoniza-se com a perspectiva de Lèvy (1993). Para o autor, as tecnologias intelectuais são responsáveis por ampliar, modificar, exteriorizar as funções cognitivas, indo além de meras extensões e das próteses. Embora Lèvy destaque a questão cognitiva, é possível identificar nos seus livros publicados, especialmente entre os anos 1993 a 2000 no Brasil, que essa mediação vai além do cognitivo, ampliando-se para uma visão sistêmica do humano que cotidianamente transforma-se em pós-humano. Para o autor essa rede sociotécnica se recompõe e reconfigura constantemente.

Para muitos de nós essas ideias não são mais ficção, mas é neste universo que vamos começar a compreender as possibilidades alvissareiras de transformação do homem ao longo de sua história. A presença dos robôs na filmografia não é recente e o nível de complexidade foi evoluindo sintonizado com as mudanças e avanços tecnológicos. Desde o Frankenstein de Mary Shelley (1818) - na literatura e depois no cinema, até os anfitriões (robôs) presentes na série Westworld antecedido por Metropolis - filme dirigido por Lang (1927), até Ex-Machine (2014), dirigido por Garland, acompanhamos o processo de evolução dessas máquinas que nascem do desejo de seus inventores de se aproximar do humano, não apenas na semelhança, mas também na tomada de decisão fazendo escolhas de forma autônoma, com livre arbítrio (ver Ex-Machine), construindo suas subjetividades.

Contudo, nesse processo observamos uma perspectiva apocalíptica marcando essas narrativas, na qual a máquina não apenas se aproxima do que é ser humano como o supera, enfatizando a dicotomia homem-máquina. E em outros momentos, tanto na literatura como no cinema, essa perspectiva implicará também um futuro de destruição, subjugação sem esperança, apresentando realidades distópicas, a exemplo do que vemos no filme $O$ exterminador do futuro (1984) dirigido por James Cameron.

Acreditamos que estamos em um momento histórico em que tais dicotomias não cabem mais, já que vivemos uma era na qual os agenciamentos sociotécnicos (LEVY, 1993) têm ocupado um lugar fundante nas relações entre a sociedade, a técnica e a cultura. Tais discussões já deveriam ter sido superadas, considerando que muito foi produzido no século XX (a exemplo da literatura citada nesse artigo), exigindo que pensemos em problemas que nos afetam no século XXI. Lemos (2018) já apontava esses aspectos ao analisar a série televisiva Black Mirror, que traz 
em alguns dos seus episódios (de forma mais explícita nos episódios $\mathrm{T} 1^{10}$ - Toda sua história; T2 - Natali T3 - Versão de Testes; T3 -San Junipero; T3 - Engenharia Reversa; T4 Metalbead) a questão do pós-humano, destacando o imbricamento homem-máquina; isto é, a relação do homem com tecnologias implantadas em seu corpo, caracterizando-os como verdadeiro ciborgue ${ }^{11}$. Nessas relações são apontados aspectos nefastos desses acoplamentos, desde a realização de atos hediondos por parte daqueles que estão nessa condição até violação das questões éticas que envolvem o respeito à privacidade do outro e a sua liberdade de escolha.

Para Lemos (2018) o ciborgue se constitui em "uma subjetividade híbrida a partir da relação íntima entre corpo, artefato e informação", isto é, um organismo cibernético, ser híbrido, com partes orgânicas e inorgânicas (2018, p. 39). Analisando os episódios da série o autor enfatiza que "o desafio do presente, e certamente será o do futuro, é o de compreender essa formação de uma subjetividade algorítmica picotada, os perfis dividuais ${ }^{12}$, mapeados e reproduzidos nos sistemas informacionais" (2018, p. 58).

Os aspectos pontuados pelo autor podem ser revisitados na série televisiva Westworld - WW - que é transmitida pela $\mathrm{HBO}$ - canal de assinatura por TV a cabo (no Brasil exibida pelas Operadoras Sky e NET entre outros) e streaming. A série teve seu primeiro episódio exibido no Brasil em outubro de 2016 e sua segunda temporada foi transmitida em novembro de 2017. A série é baseada nos filmes "Westworld - onde ninguém tem alma" (nome no Brasil) - 1973, que foi escrito e dirigido por Michael Crichton - e também em sua continuação, Futureworld, de 1976, dirigido por Richard T. Heffron. Em 1980 foi exibida a série televisiva, Beyond Westworld, com apenas 5 episódios que desconsideram a sequência cinematográfica de Futureworld e tiveram diretores diferentes para cada episódio ${ }^{13 .}$

É interessante pensar que apesar de haver uma repetição da temática que podemos ver em uma ampla cinematografia, a exemplo de AI - Inteligência Artificial de Steven Spielberg (2001), Blade Runner (Ridley Scott, 1982), Robocop (Paul Verhoeven, 1987) entre outros, nos dando a impressão de que não há mais a ser

10. Neste artigo iremos nos referir à temporada utilizando a letra $T$ em maiúsculo, seguida do número da temporada, isto é, T1 - para temporada 1.

11. Maiores detalhes dos episódios podem se consultados no livro de Lemos indicado aqui ou através do link https://pt.wikipedia.org/wiki/Lista_de epis\%C3\%B3dios de Black_Mirror . Acesso 30 abr. 2019 .

12. O termo foi também usado por Deleuze (1992) para se referir a "Os indivíduos tornaram-se "dividuais, divisíveis e as massas tornaram-se amostras, dados, mercados ou 'bancos'" citado por Lemos (2018) - ver nas referências finais.

13.Ted Post (T1-E-1), Rob Holcomb (T1-E2), Paul Stanley (T1-E3), Jack Starrett (T1-E4) e Don Weis (T1-E4). Os dois últimos não chegaram a ser transmitidos. 
dito sobre a relação homem/máquina, ainda existe uma persistência em continuar contando essa história sob distintos pontos de vista, embora evidenciando uma visão de que a máquina pode se aproximar do que é ser humano, como no filme Alita: anjo de combate, dirigido por Robert Rodriguez (2019) ou ainda o episódio 1/T01 - A vantagem de Sonnie da animação seriada Love, Death \& Robots, exibida pela Netflix em março de 2019 e dirigida por Joshua Donen, David Fincher, Jennifer Miller e Tim Miller, na qual somente no final sabemos que a personagem é um robô.

Contudo, WW vai, pelo menos na primeira temporada, nos apresentar a possibilidade de olhar essa relação sob outros pontos de vista, a exemplo da discussão sobre a memória, ética, livre arbítrio, consciência. E nas narrativas de Maeve, Bernard e Dolores (anfitriões com destaque na série) evidenciam a temática amor, família e perda. Por exemplo, as lembranças de Maeve com sua filha perdida; de Bernard com o filho morto e a relação de Dolores com seu pai. Outro ponto interessante na série é o papel das personagens femininas que se apresentam como fortes, lutando pelo seu direito de ser livre, como o caso de Maeve, Dolores e Charlotte Hale (diretora executiva da Delos e ainda não sabemos com certeza se é uma anfitriã ou um humano). Tal perspectiva sintoniza-se com as narrativas que têm como cenário o Velho Oeste que, segundo Araújo, se caracteriza em um gênero no qual "as personagens femininas são providas de pouca agência" (2013, p. 114).

Ao analisar a série exibida pela $\mathrm{HBO}$, que é o objeto deste artigo, produzida por J.J. Abrams ${ }^{14}$, Jonathan Nolan e Lisa Joy (como showrunneres), desde 2014 percebemos de forma clara a influência dos filmes Westworld e Futureworld, inclusive com referências em um dos episódios da primeira temporada ao anfitrião (como são chamados os robôs) do primeiro filme, vivido por Yul Brynner, que aparece no depósito onde ficam os robôs que não são mais utilizados ${ }^{15}$ no mundo subterrâneo. A série, diferente dos filmes anteriores, apresenta quatro mundos; o mundo elevado onde está o comando do Parque e a fábrica de androides; o mundo subterrâneo onde ficam os anfitriões que foram desativados; o mundo externo - onde vivem os humanos; e o mundo da planície onde acontecem as tramas e narrativas que envolvem os robôs e humanos - o parque com seus distintos cenários.

A saga da série parte do plot do filme "Westworld - onde ninguém tem alma", de 1973, traz a Delos como uma empresa que cria um parque no qual o visitante pode ser o que quiser, interagindo com os anfitriões que existem para satisfazer os seus

14. Abrams é considerando pelos seus pares como um dos mais inovadores produtores do contexto contemporâneo de narrativas fílmicas e seriadas.

15. Não é intenção deste artigo discutir os filmes e séries desenvolvidos anteriormente, mas em alguns momentos podemos referenciá-los. 
distintos prazeres. A diferença básica nesse filme para distinguir os anfitriões dos visitantes é o detalhe das mãos, especialmente os dedos, que os cientistas da Delos não conseguiram reproduzir com fidelidade, aspecto técnico que será superado no segundo filme para alcançar a perfeição total na série, isto é, a impossibilidade de distinguir os anfitriões dos recém-chegados, como são chamados os humanos.

Nessa trilogia (os dois filmes mencionados e a série aqui analisada) podemos observar que a Delos consegue avançar tecnicamente no processo de desenvolvimento e complexidade das personalidades dos anfitriões, bem como nos cenários disponíveis no Parque, nas formas de controle e armazenamento das memórias dos recém-chegados e dos hosts. Na primeira temporada da série o mundo que predomina é o do velho Oeste, mas no filme de mesmo nome já vemos a existência de mais três mundos (Roma Imperial, Idade Média e Velho Oeste).

No primeiro filme vemos o parque ser destruído causando a morte de humanos e robôs e dois anos depois reconstruído, reaberto e apresentado no filme Futureworld de 1976, no qual se anunciam as ideias de criar um sistema de reprodução, não apenas relacionado com os aspectos físicos, mas copiando as memórias dos humanos gerando as cópias/clones quase perfeitos de representantes governamentais ou da mídia responsável pela formação de opinião. No final deste filme os repórteres vividos por Peter Fonda e Blythe Danner, que representavam a busca pela verdade - os mocinhos da história -, vão punir os criminosos, que no filme são os cientistas e empresários da Delos. Os protagonistas destroem o que pode provocar risco a humanidade. Estas duas perspectivas, do bem e do mal, vão aparecer também na série

Para Mittell (2012), o século XXI vai marcar as transformações na indústria mediática, nas tecnologias e no comportamento do público (que passam a adotar práticas criativas, expandindo os aspectos formais para além das fronteiras textuais) que contribuem para o que o autor denomina de narrativas complexas, inclusive com a mudança nas histórias de que o bem nem sempre vence o mal. A complexidade dessas narrativas

Em seu nível mais básico, é, uma redefinição de formas episódicas sob a influência da narração em série - não é necessariamente uma fusão completa dos formatos episódicos e seriados, um equilíbrio volátil. Recusando a necessidade de fechamento da trama em cada episódio, que caracteriza o formato episódico convencional, a complexidade narrativa privilegia estórias com continuidade e passado por diversos gêneros. (MITTELL, 2012, p. 36)

Nos aspectos acima mencionados percebem-se similaridades com o que 40 anos depois é visto nas séries produzidas pela $\mathrm{HBO}$ no seu pacote Premium, destacando aqui WW. Nesta série evidencia-se o protagonismo dos anfitriões, diferenciando-se 
do filme de 1973 cujo destaque era apenas o personagem do cowboy, representado por Yul Brynner.

$\mathrm{Na}$ série percebemos um avanço na caracterização dos robôs, como por exemplo Dolores, Maave e Bernard, que têm angústias e conflitos, depois do bug que vai provocar falhas no sistema desses autônomos, levando-os a ter lapsos de memória em relação às "suas vidas passadas", aproximando-os do que é marcante e estruturante no ser humano, inclusive na ambivalência entre o bem e o mal. A regra de que estes androides deveriam esquecer as suas lembranças a cada final do dia é quebrada. A partir desse momento, os robôs, como os humanos, vão lembrar dos seus "vestígios do dia", seus rastros de memórias, fragmentos que não se encaixam e são incompreensíveis em relação ao que acreditavam ser.

Mas as lembranças contínuas vão ajudá-los a organizar o quebra-cabeças de suas supostas vidas, gerando dúvidas, revoltas, angústias e vingança, já que se sentem violentados pelos humanos que os controlam. Emoções e sentimentos marcantes e definidores do que é ser humano.

A questão do esquecimento parece ser reincidente na trajetória de Nolan. No filme Amnésia (Memento, 2001), o diretor e roteirista Nolan traz a história de um personagem que tem perdas de memória, criando estratégias diferenciadas para lembrar, como, por exemplo, escrever no seu corpo palavras chave para lembrar. Outro aspecto que marca as criações deste artista é a ideia de uma tecnologia que controla e prevê o que pode acontecer com as pessoas e suas vidas, como por exemplo na série Person of Interest (2011 - produzido em parceria com J. J. Abrams). Este aspecto aparece novamente na série WW, quando vemos o Dr. Ford, personagem do ator Anthony Hopkins, cientista master das corporações Delos, responsável pela criação do parque e seus anfitriões, que atua também como um titereiro, manipulando os humanos e anfitriões que foram criados à semelhança dos seres humanos, com o objetivo de atender aos desejos dos recém-chegados, visitantes que vem ao Parque de Delos para realizar seus desejos sombrios ou não. Como uma versão mais nefasta da Ilha da fantasia (produzida por Aaron Spelling e Leonard Goldberg), série reproduzida no canal aberto na década de 80 no Brasil, na qual os visitantes iam para uma ilha paradisíaca realizar seus desejos em interação com humanos, no Parque da Delos desde o primeiro momento - quando os convidados entram - são feitas pequenas escolhas que podem definir se querem ser mocinhos ou vilões, como, por exemplo, a escolha do chapéu que vão utilizar: claro está associado ao bem e o preto ao mal. Esta representação do chapéu preto para indicar que é o vilão é herdada dos filmes de Western (vemos aqui mais uma influência do background de Nolan), como pontuou Araújo (2013). 
Assim, na série WW vemos as marcas de Nolan, inclusive no que se refere ao seu background como jogador de videogame ${ }^{16}$. Anaz destaca o uso da técnica de engenharia reversa para entender a

[...] topologia imaginada pelos criadores de Westworld é preciso mapear e analisar as imagens por uma espécie de engenharia reversa - que interpreta as imagens materializadas ou icônicas da série para se chegar aos arquétipos que as formataram -, com o objetivo de revelar os aspectos espaciais da diegese da série pensada por seus autores e as articulações simbólicas que elas estabelecem. (2018, p. 10)

Esse processo envolve resgatar as trilhas já deixadas, especialmente por Nolan em seus trabalhos anteriores, a fim de compreender a estrutura de WW. Apesar de os cientistas do Parque Delos acreditarem que têm o ambiente controlado, os robôs começam a apresentar falhas técnicas que os levam a curtos / bugs provocando a morte de humanos, violando assim as três leis criadas por Asimov e as do próprio Parque, isto é, robôs não podem ferir os humanos. Para Asimov (1971), escritor da área de ficção científica, a robótica apresenta três leis:

$1^{a}$ Lei: Um robô não pode ferir um ser humano ou, por omissão, permitir que um ser humano sofra algum mal ${ }_{i} 2^{\mathrm{a}}$ Lei: Um robô deve obedecer às ordens que lhe sejam dadas por seres humanos, exceto nos casos em que tais ordens entrem em conflito com a Primeira Lei; $3^{\text {a }}$ Lei: Um robô deve proteger sua própria existência desde que tal proteção não entre em conflito com a Primeira e/ou a Segunda Lei.

Mas em que momento podemos pensar em pós-humanos na série? Os anfitriões como robôs de serviço estão próximos aos seres humanos pela sua aparência, mas isso vai mudar quando a linha tênue que os separa é rompida com a lembrança das vidas anteriores e a emergência das emoções que afloram a partir destas recordações dolorosas ou não. Esse é o ponto marcante que insere os anfitriões da série Westworld na condição de pós-humanos que foram reconfigurados a partir da mediação das tecnologias digitais e as biotecnologias, tornando-se semelhantes ao que caracteriza os humanos.

Mas os humanos ou aqueles que são apresentados como tais na narrativa também farão a passagem. A possibilidade de se tornarem eternos, armazenando suas memórias em bancos de dados para serem inseridas depois em seus clones perfeitos, após a morte do corpo. Inicialmente, com a aprovação do indivíduo zero - o primeiro experimento indicado na série, com James Delos, presidente da empresa, o patriarca que era o mecenas de Ford, o cientista, que também tinha interesses escusos no Parque, com seus androides e visitantes.

16. Neste artigo não iremos discutir essas influências. 
Este tipo de experiência já é apresentado no filme Futureworld, mas sem o conhecimento e autorização dos visitantes, prática que será evidenciada também na série, após a experimentação com James Delos.

Aqui vemos mais um diferencial na narrativa da série: a discussão ética. Os direitos dos recém-chegados e depois dos anfitriões são totalmente violados, na medida em que os experimentos realizados são alheios e sem consentimento dos envolvidos. No contexto que estamos vivendo e especialmente para pensar essa hibridação homens - tecnologia, originando os pós-humanos - devem ser explícitos os possíveis riscos da inserção das tecnologias digitais, por exemplo, no cérebro, que podem trazer danos, conforme vemos evidenciado também na série Black Mirrow ou ainda questões relacionadas com os algoritmos que mapeiam e armazenam todos os nossos rastros na internet, especialmente nas redes sociais, invadindo a privacidade e segurança dos seus usuários.

Para validar o sucesso da semelhança dos anfitriões aos humanos são realizados testes de Turing, a exemplo do que vemos com James Delos, Bernard e William (o homem de preto) que são avaliados continuamente para determinar o quanto se aproximam dos humanos.

Na década de 50 Turing propôs o "jogo de imitação"17, em seu artigo "Computer Machinery and Intelligence", que consistia em analisar as respostas que eram emitidas para decidir quem é o humano ou quem é a máquina. $\mathrm{O}$ trabalho de Turing consistia em fazer questionamentos que pudessem distinguir o desempenho verbal da realidade incorporada. Se essa distinção não ocorre é possível provar que as máquinas podem pensar (HAYLES, 1999).

Para Hayles,

[...] no momento inaugural da era do computador, o apagamento do sem-corpo é realizado de modo que a "inteligência" se torne uma propriedade da manipulação formal dos símbolos, e não da ação no mundo da vida humana. O teste de Turing foi para definir a agenda de inteligência artificial para as próximas três décadas. Na pressão para conseguir máquinas que possam pensar, os pesquisadores realizaram repetidas vezes o apagamento da incorporação no coração do teste de Turing. Tudo o que importava era a geração formal e manipulação de padrões informacionais. $(1999, \mathrm{xi})^{18}$

17. Em 2015 foi exibido um filme no cinema dirigido por Morten Tyldum com o mesmo nome que apresenta a origem das ideias de Turim e seu trabalho.

18. Here, at the inaugural moment of the computer age, the erasure of embodiment is performed so that "intelligence" becomes a property of the formal manipulation of symbols rather than enaction in the human life- world. The Turing test was to set the agenda for artificial intelligence for the next three decades. In the push to achieve machines that can think, researchers performed again and again the erasure of embodiment at the heart of the Turing test. All that mattered was the formal generation and manipulation of informational patterns. 
Nos testes realizados em WW vemos a linha tênue que separa os androides dos humanos, tornando impossível identificá-los a não ser que não passem no teste, como no caso de James Delos que, mesmo submetido a inúmeros testes, sempre falhava.

Podemos relacionar a tecnologia utilizada pelos cientistas e técnicos de WW, como um Cookie, que gera "uma cópia de um cérebro humano que através de algoritmos, age como a consciência do próprio indivíduo. Esse sistema é uma forma mais sofisticada de objeto do que se vem chamando de "Internet das Coisas (IoT)" (LEMOS, 2018, p. 70).

Assim, os androides da série passam por um processo de evolução chegando à condição de ciborgues - de pós-humanos, híbridos construídos da interface entre a tecnologia, seus artefatos e banco de informações que aumentam a ecologia cognitiva desses seres, tornando-se diferenciados dos demais. Dentro desse contexto, concordamos com Lemos (2018) quando registra que esses acoplamentos poderão surgir da interface dos objetos inteligentes e os bancos de dados. $\mathrm{O}$ que vemos em Westworld é a manipulação da memória e da consciência não apenas dos anfitriões, mas também dos visitantes, através de chips - objetos microeletrônicos que controlam seus comportamentos e escolhas, especialmente no primeiro caso. Contudo, os bosts desejam se libertar, evidenciando o plot sempre presente na cinematografia de que a máquina se vinga do seu criador/dominador - o homem - e se liberta e quer vingança. Nessa série vemos também emergir uma discussão que aponta que o comportamento dos anfitriões muitas vezes indica características que são atribuídas aos humanos e não às máquinas.

A ideia da algocracia ${ }^{19}$ implícita na série desvia o controle das mãos de um grupo para os pós-humanos que se constituem dessa hibridação homem-máquina. Na primeira temporada, culminando no episódio 10, vemos a doce, bela e romântica Dolores se transformar em uma personagem vingativa que busca se libertar do controle de Ford e do Parque, como uma salvadora de anfitriões, marcando o início da sua consciência. Na segunda temporada Dolores não medirá esforços para alcançar seus objetivos, inclusive ferindo anfitriões quando necessário, a exemplo de Teddy, seu par amoroso na série. Já a consciência de Maeve será marcada por dor e sofrimento ao resgatar suas memórias (MULLEN, 2018).

Em dezembro de 2018 foi lançado o Dossiê Posthumains em séries ${ }^{20}$ na Revista online Tv/Series, organizada por Hélène Machinal and Monica Michlin. Nessa edição a discussão circula entre a categoria pós-humano e as ficções televisivas

19. Utilização do sistema algorítmicos complexos para controle social.

20.Disponível na URL: https://journals.openedition.org/tvseries/2757? lang=en 
Black Mirror e Westworld. O artigo de Favard (2018), como já destacado neste texto, registra a longa história da ficção científica e cinematográfica para dá vida aos robôs e destaca o histórico de Nolan, mas levanta um questionamento: considerando essa exploração do tema através da complexidade da narrativa serializada, o que mais Westworld pode dizer que não foi dito ${ }^{21}$ ? E o autor responde:

A resposta aqui proposta é que ela incorpora o discurso sobre a consciência artificial em uma trama altamente reflexiva, porque parece estar ciente de que é uma série. Como no caso de Data [androide da série Star Trek, dirigida por Gene Roddenberry e exibida na década de oitenta e noventa] não podemos ter certeza de que Westworld tenha uma consciência, ou seja meramente o resultado de sua "programação", mas sua disposição em enfatizar seus mecanismos narrativos mais básicos a distingue de muitas outras séries de ficção científica, à exceção, veremos, de Person of Interest, a primeira incursão de Jonathan Nolan na abordagem reflexiva da consciência artificial na televisão ${ }^{22}$

A série WW inova na sua perspectiva de atribuir consciência às máquinas, tornando-as tão semelhantes aos humanos que muitas vezes é impossível distinguilas. Essa consciência torna-as capazes de assumir a liderança de suas vidas. Os anfitriões dessa narrativa lutam por suas histórias, sinalizando a emergência de uma nova condição de pós-humanos que pode sair das telas e narrativas ficcionais para a nossa vida cotidiana. A busca pelo controle de suas vidas e por recomeços por parte dos ciborgues já foi evidenciada nas versões cinematográficas de Frankenstein, a exemplo de As Crônicas de Frankenstein, criada por Benjamin Ross, Barry Langford e exibida a partir de 2015 pela Netflix. Nessa série, de três temporadas, os humanos que retornaram após a morte, a partir de experiências médicas, tomam consciências de suas memórias e após o momento inicial de desejo de vingança só lhes resta seguir em frente.

$\mathrm{O}$ universo dos jogos digitais também apresenta narrativas que destacam a presença dos pós-humanos. Nos anos noventa, Hayles, citada por Green e Bigum (1995), afirmava que o sujeito que está em contato direto com os jogos eletrônicos vive uma interação contínua entre seu sistema nervoso e o circuito do computador, constituindo-se em um ciborgue. Nossos alunos dos diferentes de níveis de ensino interagem cotidianamente com esses aparatos tecnológicos que podem estimular

21. Todas as traduções são responsabilidade das autoras

22.But after decades of exploring the topic through the prism of narrative complexity and serialized storytelling, what else can Westworld say that has not already been said within the frame of the television screen? The answer proposed here is that it embeds its discourse on artificial consciousness in a highly reflexive plot because it appears to be aware that it is a series. As in the case of Data, we can not be sure that Westworld has a consciousness, or is merely the result of its "programming", but its willingness to emphasize its most basic narrative mechanisms distinguishes it from many other science fiction series, with the exception, we will see, of Person of Interest, Jonathan Nolan's first foray into the reflexive approach of artificial consciousness on television. 
distintas funções executivas, a exemplo da memória, da flexibilidade cognitiva, controle inibitório, entre outros (ALVES, 2018, ALVES e SOUZA, 2019). Mas a escola e a academia ignoram o potencial das narrativas interativas, não apenas para pensar na formação do homem contemporâneo, na sua condição pós-humana, mas especialmente nos processos de aprendizagem prazerosos que poderiam fluir nos ambientes escolares e acadêmicos.

\section{O PÓS-HUMANO É AGORA!}

A provocação feita por este dossiê $\mathrm{O}$ pós-humano é agora! nos desperta para ir além das narrativas ficcionais propostas pelo cinema, séries televisivas, livros, jogos digitais e histórias em quadrinhos, enfim, diferentes produções culturais. Nos provoca a pensar que somos seres pós-humanos vivendo conectados em distintas redes que criam ramificações que vão ampliando e modificando nosso corpo e todas as suas funções. Ser pós-humano, como vimos neste artigo, não se limita apenas aos implantes no nosso corpo, mas a nossa interação com as distintas tecnologias para além do digital, possibilitando performances não apenas estéticas, mas cognitivas, sociais, políticas e culturais. Os conteúdos apresentados pelos produtos de entretenimento foram importantes para anunciar essas mudanças e trazer para o centro as discussões que devem ser aprofundadas.

A narrativa de WW é crível para o mundo ficcional que foi criado e toca em questões importantes para discutirmos na sociedade contemporânea. Na série vemos a presença das impressoras 3D delineando e produzindo corpos de seres similares aos humanos, animais, objetos, etc. Esta tecnologia já vem sendo utilizada para distintos fins, inclusive para produzir mãos robóticas, por exemplo, ajudando a pessoas que tiveram algum tipo de dano físico que pode comprometer suas performances.

A série WW nos provocou a pensar na sociedade que já estamos vivendo, na qual vemos implantes neurais potencializando nossas habilidades, carros que andam sozinhos, drones feitos para matar e não podemos esquecer o marco que foi ver a clonagem de Dolly (1996) ${ }^{23}$, Deep blue (computador que derrotou o campeão de

23. Maiores informações disponíveis na URL: https://revistagalileu.globo.com/Ciencia/ noticia/2016/07/como-foi-clonagem-da-ovelha-dolly.html . Acesso 30 mar. 2019. 
xadrez Garry Kasparov, em 1996) ${ }^{24}$ e Watson da IBM que vem sendo utilizado em distintos segmentos na sociedade ${ }^{25}$.

Neste mundo, assim como o mundo do WW, temos que estar atentos às questões éticas - sim, somos ciborgues, mas queremos ter o direito de decidir o que deve dialogar com o nosso corpo (aqui compreendendo o corpo para além da dicotomia mente-corpo). Será que os drones que têm sido desenvolvidos para guerras e combates saberão decidir e tomar decisões sobre quem deve ou não morrer em um combate? Será que os carros sem motoristas estão preparados para tomar decisões?

WW também nos provoca a pensar na perfeição do homem e do universo, a partir da intertextualidade com o Homem Vitruviano, de Da Vinci, que aparece em uma das aberturas da série WW, símbolo da simetria básica do corpo humano e, por extensão, para o universo como um todo. Será que alcançaremos essa perfeição enquanto pós-humanos?

Em WW podemos perceber claramente o vínculo da tríade poder - cultura - sociedade, nas relações dos que produzem novos conhecimentos e tecnologias sintonizadas com a evolução cultural e tecnológica que está presente na sociedade contemporânea, promovendo formas diferenciadas de poder.

Outro ponto também evidenciado na série é a violência que tem se tornado marca das produções premium da HBO, a exemplo de Games Of Thrones, Breaking Bad, entre outros. Araújo (2013), ao analisar a série Breaking Bad, pontua que depois de várias batalhas legais com a $H B O$, a justiça americana decidiu que os canais premium estariam protegidos pelo direto à liberdade de expressão, assegurado pela Primeira Emenda da Constituição dos Estados Unidos, possibilitando que suas narrativas exagerem em cenas de violência que reproduzem e espetacularizam a sociedade do medo e do ódio que vem emergindo no mundo contemporâneo.

E por fim, as questões de vigilância também são evidenciadas na narrativa, através do que vemos no mapa do mundo subterrâneo onde estão os cientistas e técnicos do Parque que controlam e vigiam todas as ações realizadas não apenas pelos hosts, mas pelos recém-chegados. Discussões que são da ordem do dia e vem sendo reproduzidas nas narrativas audiovisuais, especialmente nos seriados que como produtos culturais refletem o que ocorre no mundo contemporâneo.

E a escola? Como os espaços formadores como a escola e universidade vem dialogando com estes cenários?

24. Maiores informações disponíveis na URL: https://veja.abril.com.br/blog/reveja/demasiadohumano-ha-20-anos-kasparov-era-esmagado-por-deep-blue/. Acesso 30 mar. 2019.

25. https://www.ibm.com/watson/br-pt/ 


\section{A ESCOLA E O DESCOMPASSO COM AS NARRATIVAS CONTEMPORÂNEAS}

A leitura e consumo das narrativas seriadas vem crescendo nos últimos anos, sejam aquelas que são exibidas nos canais abertos, partindo inclusive das novelas ou minisséries inspiradas em romances brasileiros, e/ou as séries americanas. Contudo, o aparecimento de plataformas de streaming, como a Netflix ${ }^{26}$, mudou totalmente a forma de ver essas narrativas, mobilizando os consumidores a atuarem como leitores das narrativas, indo além de meros consumidores, posicionandose como protagonistas na medida em que se tornam fãs das séries, produzindo expansões transmidiáticas, como fanfictions, memes, imagens, vídeos, podcast, histórias em quadrinhos, entre outros exemplos.

Imersos nessas novas linguagens se fidelizam as histórias e utilizam o espaço das redes sociais para compartilharem suas distintas leituras das tramas que os seduzem, ou simplesmente para consumirem o que é produzido pelos seus pares.

Independente de essas histórias serem veiculadas nos canais fechados, são encontradas formas, nem sempre lícitas, de ter acesso ao conteúdo e fazer parte da legião de fãs de uma franquia, a exemplo do que aconteceu no dia 15/04/19, quando foi exibido o episódio 01 da $8^{\circ}$ e última temporada de Game of Thrones que foi visto ilegalmente 55 milhões de vezes ${ }^{27}$.

Os alunos exercitam seu letramento não apenas lendo nas diferentes telas suas histórias favoritas, mas nas formas de acessá-las, analisá-las, compreendê-las e produzirem outros significados a partir dos seus interesses. Contudo, a escola e seus professores (embora também fãs e leitores/consumidores) não valorizam produções feitas por seus alunos seja do universo das séries ou dos jogos digitais, distanciando-se cada vez mais do desejo e interesse dos seus educandos.

Ao adotarem essa postura, as escolas perdem a oportunidade de criar um espaço de aprendizagem prazeroso e significativo para os alunos, tornando-os protagonistas do processo de ensinar e aprender. Além disso, preterem temas importantes e contemporâneos que são discutidos nas narrativas seriadas, a

26. Em 2007 a Netflix iniciou o seu modelo de vídeo sob demanda e ao longo dos últimos 12 anos, a receita anual da empresa cresceu de 1,2 bilhão para mais de 11,6 bilhões em apenas dez anos. $\mathrm{O}$ crescimento de assinantes também cresceu de 23 milhões em 2011 para mais de 130 milhões em 2018. Segundo o site de estatística da Netflix, a popularidade do serviço cresceu tanto que estimam que $37 \%$ dos usuários da Internet usem o Netflix. In: Netflix - Statistics \& Facts. Disponivel na URL: https://www.statista.com/topics/842/netflix/. Acesso 29 Abr. 2019. Em 2016 o Brasil estava em terceiro lugar no mercado consumidor da Netflix.

27. "A Guerra dos Tronos". Primeiro episódio da última temporada visto ilegalmente 55 milhões de vezes. Publicado em 22 Abr. 2019. Disponível na URL: https://rr.sapo.pt/noticia/148923/aguerra-dos-tronos-primeiro-episodio-da-ultima-temporada-visto-ilegalmente-55-milhoes-de-veze . Acesso 29 Abr. 2019. 
exemplo do conteúdo da série WW, já evidenciada aqui, que precisam ser analisados e discutidos em sala de aula, pois tenciona o que é viver em uma sociedade marcada pelo digital, por uma mediação que vai além da distribuição / armazenamento e gerenciamento de informações, mas nos impõe pensar o que é ser humano ou, melhor dizendo, pós-humano.

Abrir espaço para tais discussões, não significa preterir os conteúdos universais que devem / podem ser aprendidos no espaço escolar e acadêmico. Significa atribuir sentidos aos conceitos que marcam a aprendizagem nos espaços ditos formais, relacionando-os com o que vem emergindo no contexto contemporâneo, evitando leituras simplistas e de causa e efeito em torno dos temas relevantes como a violência em suas distintas facetas, a ética acesso, muitas vezes, inescrupuloso aos dados e marcas deixados pelos usuários nas redes, a liberdade de ir e vir, escolhendo o que queremos e podemos ser.

É importante ressaltar que já existem professores/pesquisadores que vêm dialogando com o universo das séries em espaços escolares e acadêmicos. Um exemplo na universidade é a experiência vivenciada por Lemos (2018) e seus alunos, no semestre de 2017.1, na Faculdade de Comunicação da UFBA, que refletiram, discutiram e analisaram, na disciplina Comunicação e Informática, o fenômeno da série Black Mirror, os temas abordados na série, relacionados com a sociedade do espetáculo e seus desdobramentos, culminando com o livro já referenciado neste artigo. O Ensino das Ciências também foi mediado pelas narrativas das séries televisivas e sistematizados nos trabalhos de Mattos E Tomaz (2017), Pereira, Menezes, Vitiello E Dominguez (2017), Freitas (2016), Palazzo (2013), Dias e Antedomenico (2010).

Assim, podemos afirmar que os conteúdos veiculados pelas linguagens audiovisuais, como o cinema, as séries televisivas, os jogos digitais, entre outros, enquanto produtos culturais trazem em suas narrativas mesmo ficcionais, discursos e temáticas que nos afetam diretamente e que podem e devem ser levados para os locus de formação em distintos níveis. Portanto, a escola e seus docentes podem e devem criar momentos para discuti-los, sintonizados com o que seus alunos vêm lendo e interagindo, contribuindo para o processo de letramento e a formação crítica dos seus alunos.

Acreditamos que a simples estratégia de ouvir os alunos, identificando o seu nível de interação, interesse e engajamento com as narrativas audiovisuais, permite aos docentes, sistematizarem práticas pedagógicas que dão voz aos seus estudantes, sintonizados com o momento que estamos vivendo, mas sem perder de vista o compromisso com um processo de ensino e aprendizagem que também valoriza a 
compreensão dos conceitos fundantes das áreas de conhecimento que estruturam a matriz curricular.

Green e Bigum (2003), no início do século XXI, já apontavam o delineamento de um "currículo ciborgue" que se estrutura mediante a transformação dos planejamentos e práticas curriculares mediadas pelas tecnologias digitais, considerando as complexas interações que tensionam o espaço escolar. Nesse contexto, a produção audiovisual também não deve ser preterida.

Assim, os resultados da análise aqui apresentados, estabelecem relações entre a narrativa da série indicada e o contexto da sociedade contemporânea, apontam preocupações relacionadas com temas emergentes como vigilância, acesso indevido e antiético com os dados gerados e armazenados a partir de algoritmos, da interface homem/máquina, ações invasivas mediadas pelas tecnologias que são acopladas para potencializar funções cognitivas, entre outras e por fim, a questão da violência que tem retornado nesse atual contexto mediado pelo medo é uma preocupação mundial.

Embora os resultados não pareçam alvissareiros, destacamos que a emergência de novas formas de hibridação que favorecem a (re)construção do pós-humano nos permitem explorar universos inusitados, potencializando novas formas de viver, aprender e amar na sociedade contemporânea, indo além de extensões e próteses para fundamentar práticas criativas e inovativas nesse cenário.

Desta forma, este artigo termina com muitos questionamentos, mas compreendendo que somos todos pós-humanos e a narrativa de WW aponta o limiar desta condição. Tais questões devem ser problematizadas em distintos cenários escolares e acadêmicos.

\section{$\overline{\text { REFERÊNCIAS }}$}

ALVES, L. R. G. (2018). Digital Games: Learning Spaces for Executive Functions Stimulation. In: Aliane Loureiro Krassmann; Érico Marcelo Hoff do Amaral; Felipe Becker Nunes; Gleizer Bierhalz Voss;. (Org.). Handbook of Research on Immersive Digital Games in Educational Environments. 01ed. Hershey: IGI Global, 2018, v. 01, p. 89-111.

ALVES, Lynn; SOUZA, Maria Carmem (2019). Westworld (WW): entre no jogo. In: SALES, Maryvalda; NONATO, Emanuel (orgs). Tecnologias Digitais, Redes e Educação: perspectivas contemporâneas. Salvador: Edufba (no prelo)

ANAZ, Silvio Antonio Luiz. (2018). Construindo séries de TV complexas: a concepção diegética de Westworld. In: Revista Famecos - mídia, cultura e tecnologia. Porto Alegre, 
v. 25, n.2, maio, junho, julho e agosto, 2018, p. 1-17. Disponível na URL: http:// revistaseletronicas.pucrs.br/ojs/index.php/revistafamecos/article/view/28492

DOI: http://dx.doi.org/10.15448/1980-3729.2018.2.28492

ASIMOV, Isaac. (1971). Eu, Robô. São Paulo: Expressão Cultura

DE ARAÚJJO, J. E. (2013). O Novo Oeste Americano: As Reconfigurações do Western a Partir do Seriado Televisivo Breaking Bad. Novos Olhares, 2(2), 2013, p. 104-118. https://doi.org/10.11606/issn.2238-7714.no.2013.69832

DIAS, Claudemir; ANTEDOMENICO, Edilson (2010). A perícia criminal e a interdisciplinaridade no ensino de ciências naturais. Química nova na escola, v. 32, n. 2, p. $67-72$

FAVARD, Florent. (2018). "The maze wasn't made for you": Artificial consciousness and reflexive narration in Westworld (HBO, 2016-), TV/Series [Online], 14 | 2018, Online since 31 December 2018, connection on01 January 2019. Disponível em: http://journals.openedition.org/tvseries/3040. Acesso em 20 Jan. 2019

FREITAS, Wagner (2016). O olhar complexo do licenciando em ciências biológicas sobre o transplante cardíaco e a série médica House MD. como instrumento de potencialização do processo de ensino-aprendizagem. 2016. Dissertação (Mestrado) Universidade Federal Rural de Pernambuco, Programa de Pós-Graduação em Ensino das Ciências, Recife, BR-PE, 2016. 163 f.

GREEN, B. \& BIGUM (1995). C. Alienígenas na sala de aula. In. SILVA, Tomas Tadeu (org.). Alienígenas na sala de aula - uma introdução aos estudos culturais em educação. Petrópolis: Vozes, 1995, p. 208-240

HARAWAY, Donna J. (2009). Manifesto ciborgues ciência, tecnologia e feminismosocialista no final do século XX. In: TADEU, Tomaz. Antropologia do ciborgue: as vertigens do pós-humano / organização e tradução Tomaz Tadeu. 2. ed. Belo Horizonte: Autêntica Editora, p. 33-118

HAYLES, Katherine. (1999). How we became postbuman: virtual bodies in cybernetics, Literature and informatic. Chicago: The University of Chicago Press

KASTRUP, Virginia. (2000). Novas tecnologias cognitivas: o obstáculo e a invenção. In: PELLANDA, Nize Maria Campos; PELLANDA, Eduardo Campos. Ciberespaço: um bipertexto com Pierre Lèvy. Artes Oficios: Porto Alegre, 2000, p. 38-54 
KUNZRU, Hari. (2009). Genealogia do ciborgues. In: TADEU, Tomaz. Antropologia do ciborgue: as vertigens do pós-humano. Organização e tradução Tomaz Tadeu. 2. ed. Belo Horizonte: Autêntica Editora, p. 120-126

LEMOS, André. (2018). Isso (não) é muito Black Mirror: passado, presente e futuro das tecnologias de comunicação e informação. Salvador: Edufba.

LEMOS, André; BITENCOURT, Elias. (2018). Performative sensibility and the communication of things - sensibilidade performativa e comunicação das coisas. Matrizes. V. 12, no. 3, set/dez, 2018, São Paulo, p. 165-188

LEVY, Pierre. (1993). As tecnologias da inteligência. Tradução Carlos Irineu da Costa. Rio de Janeiro: Editora 34

MATTOS, Thamires; TOMAZ, Tales (2017). Fiç̧ão Audiovisual e Bioética: uma análise da comodificação do humano em Orphan Black. In: $40^{\circ}$ Congresso Brasileiro de Ciências da Comunicação, 40., 2017, Curitiba. Anais... Curitiba: UP, 2017. p. 1-14.

MITTELL, Jason. (2012). Complexidade narrativa na televisão americana contemporânea. Matrizes, ano 5, no. 2, jan/jun, 2012, São Paulo, p. 29-52.

MORE, Max. (1994). On Becoming Posthuman. Extropian Journal, 1994. Disponível na URL: https://www.questia.com/read/1G1-16378926/on-becoming-posthuman. Acesso em 13 abr. 2019

MULLEN, Elizabeth. (2018). "Not much of a rind on you": (De) constructing genre and gender in Westworld (Lisa Joy and Jonathan Nolan, HBO, 2016-). TV/Series [Online], 14 | 2018, Online since 31 December 2018, connection on01 January 2019. URL https://journals.openedition.org/tvseries/3304. Acesso 20 Jan. 2019.

PALAZZO, Daniela (2013). O Corpo Feminino na Série de TV Girls. In: Seminário Internacional Fazendo Gênero, 10., 2013, Florianópolis. Anais... Florianópolis: UFSC, 2013. p. 1-11.

PEREIRA, Aline Orvalho; MENEZES, Vitor Martins; VITIELLO, Giuliana Coutinho; DOMINGUEZ, Celi Rodrigues Chaves (2017). Luz, Câmera... Ciência: Abordando as Ciências e suas relações através do filme "Interestelar" e da série "The Big Bang Theory". In: XI Encontro Nacional de Pesquisa em Educação em Ciências, 11., 2017, Florianópolis. Anais... Florianópolis: UFSC, 2017. p. 1-12.

RÜDIGER, Francisco. (2007). Breve história do pós-humanismo: elementos de genealogia e criticismo. In: Revista da Associação Nacional dos Programas de Pós-Graduação em Comunicação - COMPÓS, abril de 2007, p. 2-17 
TADEU, Tomaz. (2009). Nós, ciborgues - o corpo elétrico e a dissolução do humano. In: TADEU, Tomaz. Antropologia do ciborgue: as vertigens do pós-humano. Organização e tradução Tomaz Tadeu. 2. ed. Belo Horizonte: Autêntica Editora, p. 7-16

TADEU, Tomaz; JAMES, Donald. (2000). Pedagogia dos Monstros: os prazeres e os perigos da confusão. Belo Horizonte: Autêntica Editora.

Recebido: 1/06/2019

Aceito: 6/07/2019

Publicado: 12/07/2019 